\title{
Modelling risk adaptation and mitigation behaviour under different climate change scenarios
}

\author{
Roy Brouwer • Marije Schaafsma
}

Received: 24 November 2010 / Accepted: 26 June 2012 /Published online: 24 July 2012

(C) The Author(s) 2012. This article is published with open access at Springerlink.com

\begin{abstract}
The main objective of this study is to simulate household choice behavior under varying climate change scenarios using choice experiments. Economic welfare measures are derived for society's willingness to pay (WTP) to reduce climate change induced flood risks through private insurance and willingness to accept compensation (WTAC) for controlled flooding under varying future risk exposure levels. Material flood damage and loss of life are covered in the insurance policy experiment, while the WTAC experiment also captures the economic value of immaterial flood damage such as feelings of discomfort, fear and social disruption. The results show that WTP and WTAC are substantial, suggesting a more prominent role of external social damage costs in cost-benefit analysis of climate change and flood mitigation policies.
\end{abstract}

\section{Introduction}

Climate change poses new challenges to flood risk mitigation and disaster management in countries situated below sea level like the Netherlands. Among the most important consequences of climate change facing the Netherlands are sea level rise and an increase in extreme river discharge levels (Middelkoop et al. 2001). National climate change scenarios based on the global IPCC scenarios predict in the worst case a sea level rise up to $35 \mathrm{~cm}$ until 2050 and even up to $85 \mathrm{~cm}$ until 2100. Corresponding changes in discharge volumes in the largest rivers Rhine and Meuse are expected to cause water levels to increase up to $1 \mathrm{~cm}$ per year until 2050 (van den Hurk et al. 2007).

Three quarters of the Netherlands are at risk of flooding and therefore embanked and protected by dikes. Annual expenditures by the central government for investments and maintenance of dike and dam structures in the Netherlands along the main rivers and coast are close to one billion Euros. In addition, water boards spend another billion per year on

R. Brouwer $(\bowtie) \cdot$ M. Schaafsma

Department of Environmental Economics, Institute for Environmental Studies, VU University

Amsterdam, De Boelelaan 1087, 1081 HV Amsterdam, The Netherlands

e-mail: r.brouwer@vu.nl 
local flood protection and water level management (Ministry of Infrastructure and Environment 2011). As a consequence, flood safety levels in the Netherlands are among the highest in the world. Safety levels are highest along the coast in the western part of the country, because this is where most of the economic activities take place and big cities are found such as Rotterdam, The Hague and Amsterdam. Safety levels are also higher because of the shorter warning period for flood disasters from sea (hours) compared to flood disasters from rivers land inwards (days) (Brouwer and Kind 2005; Beckers and De Bruin 2011). The expected material damage costs along the coast in the provinces of North and South Holland where these cities are located are about 33.2 billion Euros, and are substantially higher than along the rivers Rhine and Meuse land inwards, where the expected damage costs vary between 5 million and 22 billion Euros depending on the specific dike enclosure (Kind 2011).

Flood safety levels are measured in terms of expected flood return periods or flood probabilities. Currently, the flood return period related to sea storm surges is officially once every 10,000 years along the coast in the western part and once every 1,250 years for flooding of the river Rhine land inwards and once every 250 years for the river Meuse. Due to climate change, however, these flood return periods are expected to worsen in the short term to once every 500 and 125 years for the river Rhine and Meuse respectively and increase even further in the longer term without further dike reinforcement efforts (Kok et al. 2005). Flood probabilities in the western part of the country related to sea storm surges are also expected to increase to approximately once every 4,000 years by 2040 without additional investments in the existing dike system (Maaskant et al. 2009).

In order to anticipate increased flood risks due to climate change, new flood control policies have been developed and implemented since 1998 based on the principle of managed realignment (e.g. Brouwer and van Ek 2004). Moreover, designated flood disaster zones, which can be deployed in the case of flood emergency situations, were identified in the eastern part of the country (Brouwer and Schaafsma 2012). Besides 'hard' physical infrastructure, also 'soft' adaptation and mitigation mechanisms such as private insurance have been examined. Flood risk insurance is expected to be an efficient means to share the financial implications of flood risks between private and public institutions (Pearce and Smale 2005). Proposals for public-private flood insurance schemes are, for example, found in Akter et al. $(2009,2011)$ and Aerts and Botzen (2011). Private flood risk insurance is not available yet in the Netherlands for a number of reasons, including the relatively high existing safety standards compared to surrounding countries and financial barriers related to the reinsurance of the risks of catastrophic floods (Botzen and van den Bergh 2008). The costs of flood safety are therefore currently paid by the public sector.

In this paper, we examine public perception and valuation of alternative climate change flood risk adaptation and mitigation strategies instead of increasing investments in existing dike systems to maintain the high flood safety levels in the future in a large-scale household survey covering different flood risk areas along the main rivers and coast. Choice experiments were used to elicit public preferences for the introduction of flood risk insurance and designated flood disaster zones. In the former case, individual households at risk of catastrophic flooding along the coast and the main rivers are asked to choose between different insurance arrangements, offered at different prices (insurance premiums), in anticipation of climate change conditions measured through changes in flood probabilities, inundation depths and evacuation periods. The latter two components, inundation depth and evacuation duration, are included to estimate the economic value of immaterial flood damage, such as feelings of discomfort, fear, stress and social disruption. These nonmonetary well-being effects are usually not included in economic assessments of the impacts of climate change and flooding (e.g. Stern 2006). 
In the latter case, individual households living in designated flood disaster zones in the eastern part of the Netherlands are asked to choose between controlled and uncontrolled flooding alternatives based on the same expected climate change conditions, i.e. changes in flood probability, inundation depth and evacuation period. Financial compensation is offered only in the case of controlled flooding in a designated flood disaster zone. A designated flood disaster zone is an area that will be flooded in case of emergency, i.e. under extreme weather and hydraulic conditions which present acute dangers of uncontrolled flooding of densely populated areas downstream due to unpredictable dike breaches. Households rejecting the idea of controlled flooding in designated flood disaster zones accept the financial risk of uncontrolled flooding under different climate change conditions.

In both cases this study tries to break with the long tradition that the government is solely responsible and hence accountable for flood risk and flood control management in the Netherlands. The main objective of the study is to measure the perceived risk of climate change and society's willingness to pay (WTP) to reduce or avoid these risks and willingness to accept compensation (WTAC) for an increase of these risks. The a priori expectation is that both measures are positive and substantial, and provide important additional information for cost-benefit analysis of climate change adaptation and mitigation policies.

The remainder of this paper is organized as follows. The next section introduces the choice experiment, followed in Section 3 by a description of the survey and sampling procedure. Section 4 presents the general survey results, followed in Section 5 by the estimated WTP model and associated welfare measures and in Section 6 the estimated WTA model. Finally, Section 7 concludes.

\section{The choice experiment}

\subsection{Introduction}

The choice experiment that informs this study is part of the family of stated preference methods (e.g. Hanley et al. 1998; Birol and Koundouri 2008; Carson and Louviere 2011). Preferences for environmental changes are elicited using a social survey format, such as inperson interviews. In these surveys, individual respondents are presented with information about specific environmental changes. The values of these changes are usually not accounted for in economic markets or captured through market-based instruments. Individual perception, attitudes and preferences regarding these changes and their 'non-market values' are elicited in the survey. In order to measure the effect of the suggested changes on people's welfare, respondents are typically asked for either their WTP or WTAC for the welfare gains or losses involved (e.g. Bateman et al. 2002).

Stated preference methods are rarely used in flood risk valuation studies, but their use is increasing (Brouwer et al. 2009; Botzen and van den Bergh 2009; Brouwer and Akter 2010). So far, demand for flood insurance has been examined primarily using existing actuarial data in countries where flood insurance exists (e.g. Ganderton et al. 2000; Browne and Hoyt 2000; Kunreuther et al. 2009; Michel-Kerjan and Kousky 2010). Compared to the WTP approach, asking people for their WTAC for (potential) welfare losses is a considerably less applied approach in the field of environmental risk valuation (e.g. Dekker et al. 2011), partly due to the criticism that the WTAC measure is not constrained by disposable income and can therefore result in relatively high values (e.g. Arrow et al. 1993).

As an expression of behavioural intent, public WTP and WTAC are expected to be highly dependent upon public knowledge and awareness, perception, and attitudes towards the 
particular flood risks involved (e.g. Slovic 1987; Sjöberg 2002). Risk perception and perspectives in turn differ among individuals in the same situation. They depend on personal experiences, the extent to which the risk is regarded as voluntary, under individual control and responsibility, familiar and well-understood (Wilson 1991; Beattie et al. 1998). In addition, theory tells us that WTP for a reduction in risk exposure depends on (i) the realised level of risk, which is determined by exogenous risk and self-protection activities, (ii) individual characteristics such as disposable income to protect oneself against risk, and (iii) an individual's disutility from risk exposure or risk aversion (Shogren and Crocker 1991; Bateman et al. 2005). These factors were controlled for as much as possible in the choice experiment and estimated choice models presented here through the inclusion of a wide variety of related questions in the survey about individual respondents' risk awareness, knowledge, perception, attitudes and protection measures.

\subsection{The choice experiment}

In the survey applied in this study, respondents were asked to choose between two possible future situations, compared to a baseline or 'status quo' situation of increasing flood risks in the face of climate change and doing nothing to mitigate these increasing flood risks. The economic value of a risk reduction is derived by examining individual WTP for a flood insurance policy, and the economic value of a risk increase through estimation of individual WTAC for controlled flooding. The general expectation underlying these welfare measures is that people are risk averse when their decision involves potential losses under low probability-high impact conditions, and corresponding individual choice behavior is motivated by a desire for security (Tversky and Kahneman 1979).

The design of the choice experiment used in both the WTP and WTAC versions is presented in Table 1. Of particular interest in this study is the effect of flood probability on individual choice behaviour. Current flood probabilities are low in the Netherlands since three quarters of the country is embanked. In order to circumvent poor public understanding of typical probabilistic representations of risk in valuation research (e.g. Loomis and duVair 1993), probability levels were chosen within a person's lifetime, ranging from once in the individual's lifetime to once every 5 years. This appeared to produce more meaningful risk value estimates. ${ }^{1}$ As a result, the higher flood probabilities were also expected to be more liable to sensitivity to scope compared to the insensitivity found in most low probability-high impact risk valuation research (e.g. Botzen and van den Bergh 2009). The magnitude of the proposed changes in flood probability is very high compared to the legal minimum safety level, which is officially at most once every 125 years, but not completely unrealistic for a number of reasons: (1) the frequency of (near) flood experiences along the Rhine and Meuse in years preceding the survey in 1993, 1995, 1998, 2003 and 2006; these events were widely covered in the media and are therefore more likely to shape public preferences than the official safety levels of dikes and dams; (2) the presence of weak links in the flood protection constructions along the coast and rivers (Ministerie Verkeer en Waterstaat 2003), where households will be exposed to higher risk levels in the future due to climate change without additional investments in coastal flood protection; in our sampling we focused especially on these weak links; (3) the relatively high flood risk awareness levels in the Netherlands, among others because of a nation-wide climate change and flood risk awareness campaign since 2002

\footnotetext{
${ }^{1}$ This was one of the main outcomes of the pre-test of the survey.
} 


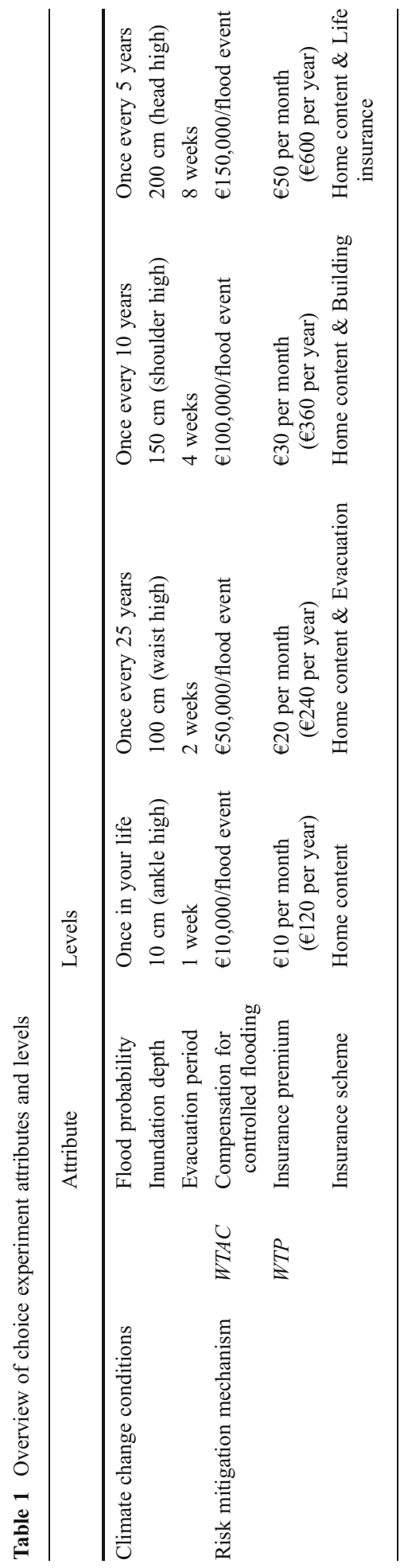


through radio and television coverage (www.nederlandleeftmetwater.nl); and (4) the absence of respondents who did not believe the suggested changes in flood probabilities in the choice experiment. $^{2}$

Inundation and evacuation were used in the choice experiment as indicators of discomfort, stress and fear. The levels of these attributes were based on available information about the national climate change scenarios and an analysis of potential future flood casualties under these existing climate change scenarios (Jonkman 2007; Beckers and de Bruin 2011). Together they represent the immaterial damage cost of flooding. Respondents were told that the insurance policies would cover all the material damage costs to home content or house structure if this insurance policy was chosen. It was decided not to include material damage costs as a separate attribute in the experimental design, because of the strong correlation between inundation depth and evacuation period on the one hand and material damage on the other. In the case of compensation for controlled flooding, it was emphasized that the financial compensation would cover the experienced discomfort, stress and fear only, over and above the fully compensated material damage costs to house and other assets.

Four different flood insurance policies were used in the WTP survey, which are currently not available in the Netherlands. With the home content insurance policy, respondents would only be paid indemnity for the damaged content of their home. The building insurance also covered all damage to the outside structure of the house due to a flood, while the evacuation insurance covered the additional costs to residents who would have to leave their house for a specified period of time in case of a flood event or the threat of such an event. The home content plus life insurance would pay indemnity in case of a catastrophic flood event resulting in the death of the policy owner or any of his or her family members.

\subsection{The choice models}

The design of the choice experiment can be translated into the following two indirect utility functions, where Eq. (1a) refers to demand for the insurance policy (WTP) and (1b) to demand for financial compensation in the case of controlled flooding (WTAC):

$$
\begin{aligned}
& U_{i j}(\text { Flood insurance })=\beta_{0}+\beta_{1} \text { Flood probability }_{i j}+\beta_{2} \text { Inundation depth }_{i j} \\
& +\beta_{3} \text { Evacuation period }_{i j}+\beta_{4} \text { Insurance type }_{i j}+\beta_{5} \text { Insurance premium }_{i j}+\varepsilon_{i j} \\
& U_{i j}(\text { Controlled flooding })=\beta_{0}+\beta_{1} \text { Flood probability }_{i j}+\beta_{2} \text { Inundation depth }_{i j} \\
& +\beta_{3} \text { Evacuation period }_{i j}+\beta_{6} \text { Compensation }_{i j}+\varepsilon_{i j}
\end{aligned}
$$

In both equations, $\beta_{0}$ is the constant and the first three parameters $\beta_{1}$ to $\beta_{3}$ refer to the coefficients related to the climate change attributes flood probability, inundation depth, and evacuation period. The expectations towards these parameters are different in Eq. (1a) and

\footnotetext{
${ }^{2}$ Only $1 \%$ of the respondents $(n=10)$ said that they thought the presented flood probabilities were too high and that they would move location if the probability of flooding would become so high in the future. None of the respondents furthermore demanded increased investments in flood protection instead of the proposed flood risk mitigation alternatives. Seventy-seven percent of all respondents indicated in a series of follow-up debriefing questions after the survey that the provided information during the interview was very clear, while two thirds had no difficulty assessing and interpreting the proposed changes in flood probabilities.
} 
(1b). Choice behaviour is expected to be positively related to the climate change variables in the case of buying insurance: the higher the flood probability and inundation and the longer the evacuation period, the higher the likelihood that someone will buy an insurance policy. The reverse relationship is expected in the case of compensation even if flooding is controlled: higher flood probabilities and inundation levels and longer evacuation times are expected to result in lower preferences for controlled flooding.

In the WTP survey (1a), the insurance premium $\beta_{5}$ is expected to have a negative effect on choice behaviour: the higher the premium, the lower the probability that someone will want to buy an insurance policy. In the WTAC survey (1b), on the other hand, the financial compensation $\beta_{6}$ is expected to influence choices in a positive way: the higher the compensation offered, the higher the likelihood of choosing controlled flooding instead of uncontrolled flooding without compensation. The inclusion of a monetary attribute (insurance premium and financial compensation) allows for the estimation of monetary welfare measures (e.g. Hensher et al. 2005) for different climate change scenarios and changes in individual components of these scenarios such as flood probabilities.

Finally, in Eq. (1a) $\beta_{4}$ refers to the different insurance policies, which were included as separate dummy variables in the estimated choice model, where home content insurance was used as the baseline category. The utility functions were estimated using mixed logit regression models (e.g. McFadden and Train 2000; Train 2003; Provencher and Bishop 2004; Hynes et al. 2008), which allowed us to capture the expected heterogeneity in public preferences due, among others, to differences in risk perception.

\section{Survey design and sampling procedure}

Except for the choice experiment, the questions in the two questionnaires (WTP for flood insurance and WTAC for controlled flooding) were identical. The final versions of the questionnaire contained 30 questions, most of which were closed-ended to minimize the interview time. The overall structure of both versions of the questionnaire consisted of three main parts.

The first part of the questionnaire focused on flood risk perception and experiences with flood events, including evacuations. In this part respondents were asked about their perceived flood risks. Respondents were first asked whether they had ever experienced a flood in the past and how often they expected the area where they live to flood. Respondents were also asked to indicate to what extent they agreed or disagreed with a number of statements regarding the probability and impacts of climate change. After these questions, they were informed about the actual flood return period in their area, that under climate change these flood probabilities were expected to increase, and the choice of either paying more taxes for improving existing dike structures to maintain current safety levels in the future or taking alternative adaptation and mitigation measures. No reference was made to the existing national climate change scenarios.

The second part of the questionnaire introduced the choice experiment, including the climate change scenarios and associated characteristics, i.e. attributes and levels, as presented in Table 1. Interviewers were trained to memorize a standard text introducing the problems associated with climate change and corresponding flood risks to ensure that the interview dialogue would have a smooth, natural flow and every respondent was given the same information. Respondents were also given the opportunity to read the text themselves if they wanted to.

A card displaying the attributes and attribute levels was used to help respondents understand (the objective of) the choice task. The representation of the attributes and their 
levels in the choice experiment is reproduced in the annex to this paper. Coloured pictograms were used to visualize different flood risk levels. In the case of flood probability and evacuation time, green was used for the lowest level followed by yellow, orange, and red for the higher levels.

A main-effects fractional factorial design was generated, approximating the necessary orthogonality conditions for these types of experimental studies (e.g. Ferrini and Scarpa 2007). The experimental design consisted of 32 choice tasks, which were blocked into eight versions of four choice tasks each in the case of flood risk insurance (WTP). Each respondent was randomly shown one of these eight versions and answered four choice tasks. Each choice task was displayed on a separate card, which was shown to the respondent. In the case of compensation for controlled flooding (WTAC), the design consisted of 28 choice tasks, blocked in seven versions of four choice tasks. ${ }^{3}$ This design was slightly smaller because the number of attributes was lower.

Each card showed two choice alternatives describing two different climate change scenarios and associated flood risks and risk mitigation possibilities, along with the option to choose none of the two. The latter 'opt-out' option, as it was explained to respondents, implied facing the increasing climate change induced flood risks in the future and choosing not to mitigate them through the purchase of an insurance policy or compensation in the event of a flood. The additional mitigation costs in this opt-out alternative were therefore zero. An example of a choice card for the WTP version is presented in Fig. 1. Respondents who chose the opt-out were asked in a follow-up question for the reasons underlying their choice. In order to make sure respondents had a clear understanding of the choice task, they were first asked to make their choice using an instruction card. Here, they were allowed to ask questions about the choice task before the experiment started.

The third and final part of the questionnaire was again identical for both versions and contained questions about respondents' demographic and socio-economic characteristics, including age, gender, education level, household composition and income, and a number of debriefing questions to assess respondents' understanding of the choice task and supporting information.

The survey and choice experiment were pre-tested through face-to-face interviews in five different pre-test rounds in May 2006 in areas with different flood risk levels, conducted by trained interviewers. The choice cards and supporting information related to the choice experiment were modified several times during these pre-tests to improve respondent understanding and develop clear and easily understandable choice tasks and representation of flood risks.

The main survey was carried out in June 2006, targeting 800 households over a period of 4 weeks. Six hundred households who live in different flood risk areas directly at the waterfront protected by dikes received the WTP for flood insurance version, and 200 households living in a potential flood disaster zone completed the version with WTAC for controlled flooding. Most areas experienced flooding or had been at threat of flooding in the past one or two decades. Interviews were held in selected cities, towns and villages along the Dutch coast (Den Helder, Scheveningen, The Hague and Vlissingen) and the rivers Meuse (Wijk en Aalburg, Den Bosch, Hedel and Heusden) and Rhine (Zaltbommel and Nijmegen along the Rhine-tributary Waal and Deventer and Zutphen along the Rhine-tributary IJssel) for the WTP version of the questionnaire. The official flood safety norms along these rivers allow a flood risk probability of once every 1,250 to 125 years. The safety standards for the

\footnotetext{
${ }^{3}$ Each version was used more or less equally often. On average, 73 respondents answered each version in the WTP survey and 28 respondents in the WTAC survey.
} 


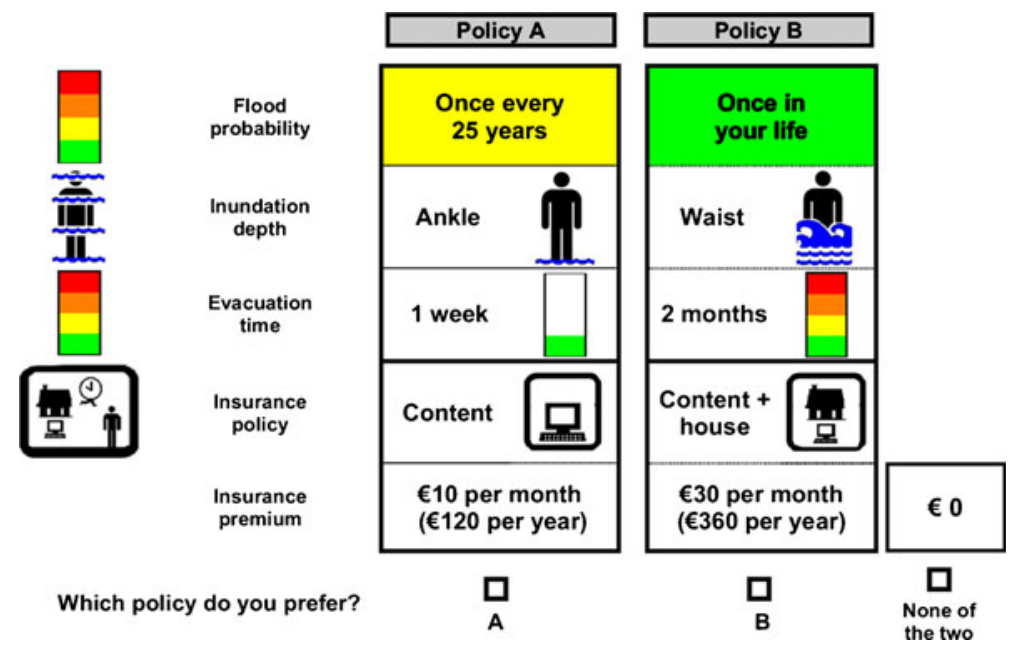

Fig. 1 Example choice card WTP for flood insurance

coastal areas are much higher, between once every 4,000 years (Vlissingen) and once every 10,000 years (Den Helder, The Hague and Scheveningen). However, these coastal locations have been identified as so-called 'weak links' by the Dutch Government, indicating that the actual risk levels at these locations are significantly higher than the official safety norm (Ministerie Verkeer en Waterstaat 2003). The interview locations are presented in Fig. 2. The number of interviews per location is presented between brackets. The WTAC version of the questionnaire was implemented in two different potential flood disaster zones along the rivers Meuse (in the villages of Ravenstein, Herpen and Lith) and Rhine (in the villages of Ooij, Millingen, Herpen and Leuth).

Interviews were carried out face-to-face and door-to-door by calling upon people living in low-level houses (flats were excluded from the sample) directly at the waterfront behind dikes or in some cases protective dunes along the coast during daytime and early evening. The 600 interviews using the flood insurance version of the questionnaire were roughly equally divided between the coastal locations and the riverside locations. The survey results will be presented in the next sections.

\section{Sample characteristics}

The demographic and socio-economic characteristics of the sample are presented in Table 2. Fifty-five percent of the respondents were women and the respondents' average age was 49 years. Respondents had to be 18 years or older to be allowed to participate in the survey. Most respondents (45\%) fall in the age group 40-60 years. About $45 \%$ of the respondents had children. The average household size was 2.6 , which is slightly higher than the national average of 2.3 (Statistics Netherlands 2007). Average disposable household income was 2,380 euro per household per month, which is more or less the same as the national average of 2,335 euro per household per month (Statistics Netherlands 2007). Half of the sample had a college, university or higher professional education degree. Two thirds owned the house in which they lived, a third rented. As expected, household income and house ownership are significantly correlated (Pearson $\mathrm{r}=0.465 ; p<0.001$ ). Due to the study's geographical focus 


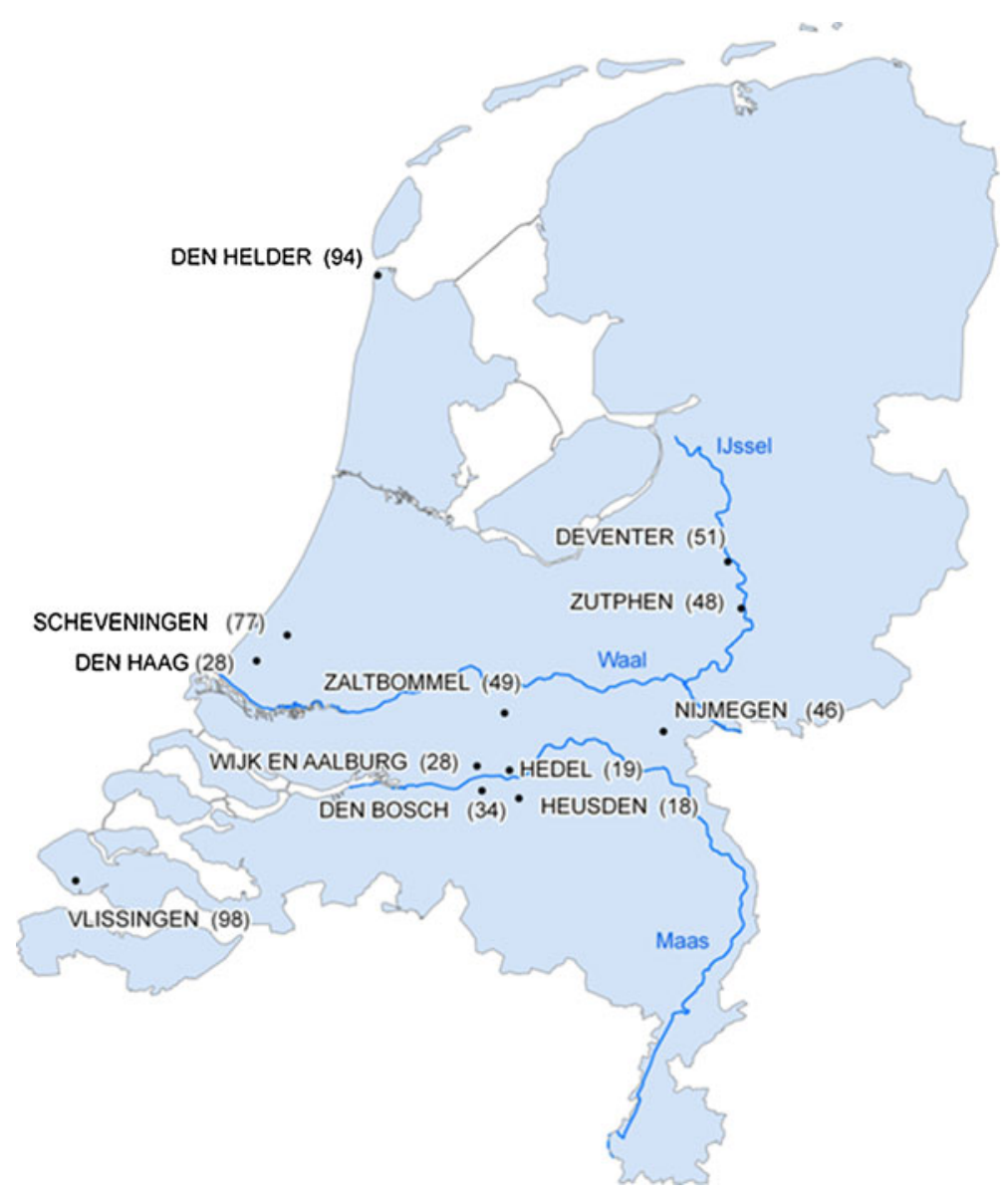

Fig. 2 Interview locations along the coast and main rivers

on rivers and coast line, the spatial distribution of the sample was skewed. The sample was, however, representative for the country as a whole based on household composition and income. Younger and lower educated people were somewhat underrepresented.

Household perception of the climate change induced flood risks was of particular interest here. A number of indicators and measurement scales were used in the survey for risk perception and attitudes (Fig. 3). Flood risk perception was measured on a semi-itemized

Table 2 Demographic and socioeconomic characteristics of the whole sample $(n=800)$
Sample characteristic

Share male respondents (\%)

44.7

Average respondent age (years)

Average household size

Percentage households with children

44.0

Percentage higher educated

Average net monthly household income (€)

2,380

Percentage house owner 


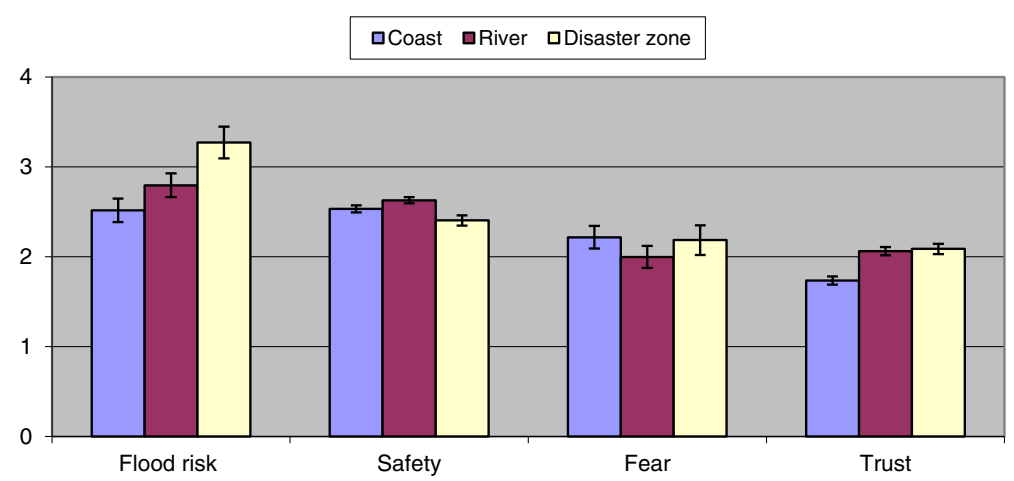

Fig. 3 Indicators of average flood risk perception, safety, fear of flooding and trust in flood emergency plans in different flood risk zones for the whole sample $(n=800)$. Explanatory notes: Flood risk perception and fear are measured on a scale from 0 to $10(0=$ no risk/fear at all; $10=$ extremely high risk/fear $)$ and safety and trust on a scale from 0 to $4(0=$ not safe/no trust at all; $4=$ very safe/complete trust $)$

measurement scale from zero (no risk at all) to ten (extremely high risk) and compared to other risky events and activities, including smoking, driving a car, flying, sunbathing and a terrorist attack. Sixteen percent of the sample had been personally affected by one or more floods in the past, while $21 \%$ had been evacuated due to flooding or the risk of flooding. A distinction was made between respondents living inside and outside designated flood disaster zones along the main rivers and respondents living along the coast. Flood experience was lower along the coast (12\%) than along the rivers $(20 \%)$. Evacuation experience was very high in the potential flood disaster zones (46\%) compared to households living along the coast $(3 \%)$ or outside flood disaster zones along the rivers $(21 \%)$.

The observed differences for flood risk perception in Fig. 3 between the three subsamples are statistically significant at the $5 \%$ level. ${ }^{4}$ Public flood risk perception was highest in the potential flood disaster zones and lowest along the coast conform current flood safety standards. Across all sub-samples, a third of the respondents perceived climate change induced flood risks as riskier than or equally risky as the other risks they faced in their daily life. Relative risk perception (measured as the score between 0 and 10 for flood risk perception divided by the average score for other risk events) was the same along the coast and the rivers, but as expected higher in the potential flood disaster zones where $45 \%$ of the sample rated flood risks higher than all the other risks summed together.

Public feelings of safety from flooding were also significantly lower in the designated flood disaster zones compared to coastal and other river areas. The difference between the latter two (coast and river) is not statistically significant. Differences between the scores for fear of floods in Fig. 3 are not statistically significant between the three sub-samples. Households living along rivers inside and outside flood disaster zones trusted existing emergency plans significantly more than households living along the coast. Five percent of the entire sample had no trust whatsoever in existing flood emergency plans. Almost $30 \%$ of the whole sample did not know whether a flood disaster emergency plan existed for the area where they live. Another interesting detail is that almost $15 \%$ of the sample believed that they were insured against flood damage even though such insurance does not exist in the Netherlands.

${ }^{4}$ Differences were tested using the non-parametric Mann-Whitney test. Test results are available from the authors. 
Finally, significant flood risk perception differences were found between men and women, and for higher and lower educated and income earning groups. Women rated the risk of flooding significantly higher than men, and lower educated and lower income groups also perceived flood risks significantly higher. ${ }^{5}$ Similarly, lower educated and lower income groups felt less safe from flooding than higher educated and higher income groups.

\section{Demand and willingness to pay for flood insurance}

The estimated choice model presented in Table 3 is highly significant. The pseudo R-square of $18 \%$ is acceptable for this type of cross-section panel data analysis (Louviere et al. 2000). The mixed logit model was estimated in NLOGIT version 4.0 and accounts for the panel data structure of the choice model. The coefficient estimates for the attributes and additional explanatory variables are presented in the second and third column of Table 3 . In the mixed logit model, random parameters are included for all attributes, except price. A normal mixing distribution is applied for the random coefficients associated with flood probability, inundation depth and evacuation period, and a uniform distribution for the dummy variables associated with the different insurance types. The estimates of the standard deviations of the random parameter distributions are presented in the fourth and fifth column of Table 3 . If the standard deviation is significant, this suggests that the attributes representing future climate change conditions are valued significantly different across individual respondents, and hence display preference heterogeneity. The last two columns present the estimated marginal WTP values for each of the flood risk attributes and the corresponding standard error. ${ }^{6}$ Marginal WTP is found by simply dividing the coefficient for the relevant non-monetary attribute by the coefficient of the monetary attribute (Hensher et al. 2005), in this case the insurance premium respondents were asked to pay.

A majority of the respondents (in $83 \%$ of the choices respondents made) preferred to buy flood insurance instead of not buying flood insurance in the face of climate change and increasing flood risks. This can also be seen from the significant positive outcome of the alternative specific constant (ASC). The outcome for the error component is highly significant at the $1 \%$ level too and indicates the presence of heteroskedasticity, i.e. respondents perceived the two hypothetical scenarios distinctly different from the existing situation.

The attributes are all statistically significant except those associated with the evacuation period and life insurance. Hence, although respondents were interested in buying evacuation insurance besides home content insurance, they did not take the evacuation time period into consideration when they made their choices. No preferences exist for life insurance over a general home content insurance. This suggests that respondents did not consider the future climate change flood scenarios as life-threatening. As expected, the insurance premium had a significant negative influence on choice behaviour, and also the direction of influence of the other attributes is as expected. Preference heterogeneity is detected for all attributes except the evacuation period. Higher flood probabilities resulted in a higher likelihood of choosing flood insurance as a risk mitigation strategy. The same applies for inundation depth.

Home content insurance is the baseline level for the insurance dummy attributes. Hence, compared to the home content insurance, public preferences were significantly higher for a building and evacuation insurance. Building insurance is most significant

\footnotetext{
${ }^{5}$ Test results are available from the authors.

${ }^{6}$ Standard errors for marginal WTP were estimated using the Krinsky and Robb (1986) procedure.
} 
Table 3 Estimated choice model WTP for flood insurance

\begin{tabular}{|c|c|c|c|c|c|c|}
\hline \multirow[t]{2}{*}{ Explanatory variables } & \multicolumn{2}{|c|}{ Parameter estimates } & \multicolumn{2}{|c|}{$\begin{array}{l}\text { Standard deviations of } \\
\text { parameter distributions }\end{array}$} & \multicolumn{2}{|c|}{ Marginal WTP } \\
\hline & $\begin{array}{l}\text { Coefficient } \\
\text { estimate }\end{array}$ & $\begin{array}{l}\text { Standard } \\
\text { error }\end{array}$ & $\begin{array}{l}\text { Coefficient } \\
\text { estimate }\end{array}$ & $\begin{array}{l}\text { Standard } \\
\text { error }\end{array}$ & Mean & $\begin{array}{l}\text { Standard } \\
\text { error }\end{array}$ \\
\hline ASC & $1.929 * * *$ & 0.328 & & & & \\
\hline \multicolumn{7}{|l|}{ Flood attributes } \\
\hline Flood probability & $2.510 * *$ & 1.204 & $6.305^{* * *}$ & 1.756 & 54.357 & 24.396 \\
\hline Inundation depth & $0.002 * *$ & 0.001 & $0.005 * * *$ & 0.002 & 0.033 & 0.018 \\
\hline Evacuation time & 0.026 & 0.021 & 0.088 & 0.0655 & 0 & \\
\hline \multicolumn{7}{|l|}{ Insurance scheme attributes } \\
\hline Building insurance & $0.691 * * *$ & 0.162 & $1.157 * *$ & 0.533 & 14.961 & 2.984 \\
\hline Evacuation insurance & $0.678^{*}$ & 0.395 & $2.411 *$ & 1.355 & 14.677 & 8.343 \\
\hline Life insurance & 0.068 & 0.134 & $1.218^{* *}$ & 0.528 & 0 & \\
\hline Insurance premium & $-0.046 * * *$ & 0.004 & & & & \\
\hline \multicolumn{7}{|l|}{ Additional variables } \\
\hline $\begin{array}{l}\text { Flood probability } \times \\
\text { coastal/river zone resident }\end{array}$ & $-4.379 * * *$ & 1.602 & & & & \\
\hline Individual risk perception & $0.237 * * *$ & 0.094 & & & & \\
\hline $\begin{array}{l}\text { Insurance premium } \times \\
\text { high income group }\end{array}$ & $0.022 * * *$ & 0.006 & & & & \\
\hline $\begin{array}{l}\text { Standard deviation of } \\
\text { error component }\end{array}$ & $2.188 * * *$ & 0.372 & & & & \\
\hline \multicolumn{7}{|l|}{ Model summary statistics } \\
\hline Log likelihood function & -1182.911 & & & & & \\
\hline Adjusted $R^{2}$ & 0.181 & & & & & \\
\hline Number of observations & 1635 & & & & & \\
\hline Number of respondents & 410 & & & & & \\
\hline
\end{tabular}

${ }^{*} p<0.1 ; * * p<0.05 ; * * * p<0.01$

in the estimated choice model. The difference between building and evacuation is, however, not statistically significant, indicating that respondents valued them the same. Marginal WTP for both the building and evacuation flood insurance is 15 Euro per household per month (over and above a home content insurance). In 2006, house owners in the Netherlands paid on average approximately 14 Euros per month for existing building insurance covering fire damage (Dutch Insurance Industry 2011). Respondents in our sample were hence willing to pay a similar amount of money for the same insurance covering flood damage.

Marginal WTP for insuring against the risks associated with an increase in the flood return period by 1 year is 54 Euros per household per month (648 Euros per household per year), while marginal WTP for insuring against the risks associated with an increase in inundation depth by $10 \mathrm{~cm}$ is 33 Eurocents per household per month or 4 Euros per year. Marginal WTP for the increase in flood probability seems high, which is probably due to the high flood probabilities used in the design of the choice experiment. However, Botzen and van den Bergh (2012) found annual WTP values for flood risk insurance ranging between 467 and 522 Euros per household per year if the flood probability would increase from once 
every 1250 years to once every 100 years (the highest flood probability level in their choice experiment. $^{7}$

Turning to the additional variables included in the choice model in Table 3, subjective and objective risk measures were applied and both appeared to influence preferences for flood insurance. Subjective risk was measured through an individual respondent's risk perception (see Section 4). The positive sign for risk perception indicates that the higher a respondent perceived the future risk of flooding, the more likely he or she was to choose flood insurance. The risk zone variable measures whether people lived along the coast or the main rivers, and is interacted with the flood probability attribute. The dummy for risk zone has the value one if a respondent lived along one of the main rivers. Hence, the negative relationship for risk zone and flood probability implies that, as expected, respondents living along the coast valued an increase in flood probability higher due to the higher expected damage costs along the coast (see Section 1).

Finally, income and hence ability to pay also played as expected a significant role when assessing demand for flood insurance. The interaction term between insurance premium and household income in Table 3 indicates that higher income groups (respondents earning more than $€ 3,500$ per month) were more likely to choose flood insurance with a higher premium.

\section{Demand and willingness to accept compensation for controlled flooding}

Also the estimated mixed logit choice model for controlled flooding presented in Table 4 is highly significant. The model is estimated in the same way as for flood insurance. It accounts for the panel structure of the data, applies a normal mixing distribution for the random coefficients associated with inundation depth and evacuation period, and includes a highly significant error component to control for heteroscedasticity between the hypothetical alternatives. The pseudo R-square of the model presented in Table 4 is high (twice as high as for flood insurance), and we find a positive disposition again towards compensation for controlled flooding as can be seen from the significant positive outcome of the ASC. A large majority of the respondents living in potential flood disaster zones preferred controlled flooding and compensation (in $96 \%$ of the choices respondents made) instead of uncontrolled flooding and no compensation when faced with increasing risks of flooding. As expected, all coefficients for the future flood characteristics are now negative: the higher the flood probability, the inundation depth or the evacuation time period, the less likely respondents preferred controlled flooding. This time also the evacuation time period is highly significant, possibly due to the fact that the number of respondents who had experience being evacuated is much higher in this sample. The compensation amount has a significant positive effect on choices: the higher the offered compensation for the experienced discomfort and stress, the higher the probability that someone preferred controlled flooding.

The choice model presented in Table 4 differs in an important way from the model presented in Table 3 in that we find a highly significant quadratic effect for flood probability, indicating that respondents felt increasingly uncomfortable at higher future flood probabilities. Such a quadratic effect could neither be detected in the flood insurance model nor for

\footnotetext{
${ }^{7}$ Under the assumption of full coverage of the expected average damage costs, which could vary between 40 and 120 thousand Euros per household per flood event, and no government relief would be provided as in this study.
} 
Table 4 Estimated choice model WTAC for controlled flooding

\begin{tabular}{|c|c|c|c|c|c|c|}
\hline \multirow[t]{2}{*}{ Explanatory variables } & \multicolumn{2}{|l|}{ Parameter estimates } & \multicolumn{2}{|c|}{$\begin{array}{l}\text { Standard deviations of } \\
\text { parameter distributions }\end{array}$} & \multicolumn{2}{|c|}{ Marginal WTP } \\
\hline & $\begin{array}{l}\text { Coefficient } \\
\text { estimate }\end{array}$ & $\begin{array}{l}\text { Standard } \\
\text { error }\end{array}$ & $\begin{array}{l}\text { Coefficient } \\
\text { estimate }\end{array}$ & $\begin{array}{l}\text { Standard } \\
\text { error }\end{array}$ & Mean & $\begin{array}{l}\text { Standard } \\
\text { error }\end{array}$ \\
\hline ASC & $11.356^{* * *}$ & 1.888 & & & & \\
\hline \multicolumn{7}{|l|}{ Flood attributes } \\
\hline $\begin{array}{l}\text { Flood probability } \\
\text { (quadratic) }\end{array}$ & $-46.738 * * *$ & 6.075 & & & & \\
\hline Inundation depth & $-0.007 * * *$ & 0.002 & $0.015 * * *$ & 0.002 & $-1,178.7$ & 611.1 \\
\hline Evacuation time & $-0.170 * * *$ & 0.048 & $0.319^{* * *}$ & 0.064 & $-27,645.6$ & $12,670.8$ \\
\hline Compensation & $0.616 \cdot 10^{-5 * * *}$ & $0.169 \cdot 10^{-5}$ & & & & \\
\hline $\begin{array}{l}\text { Standard deviation of } \\
\text { error component }\end{array}$ & $6.339 * * *$ & 1.234 & & & & \\
\hline \multicolumn{7}{|l|}{ Model summary statistics } \\
\hline Log likelihood function & -464.495 & & & & & \\
\hline Adjusted $R^{2}$ & 0.371 & & & & & \\
\hline Number of observations & 676 & & & & & \\
\hline Number of respondents & 169 & & & & & \\
\hline
\end{tabular}

${ }^{*} p<0.1 ; * * p<0.05 ; * * * p<0.01$

the other flood characteristics inundation depth and evacuation time in both models. Whereas marginal WTP for inundation depth and evacuation time is constant, marginal WTP for increasing flood probabilities is non-linear and depends on the level of flood probability. This is illustrated in Figure 4. Marginal WTAC for controlled flooding doubles from 60 to 120 thousand Euros per household per flood event if the future flood probability changes from once every 250 years to once every 125 years. If the flood probability increases further to say once every 50 years, marginal WTAC triples to just over 300

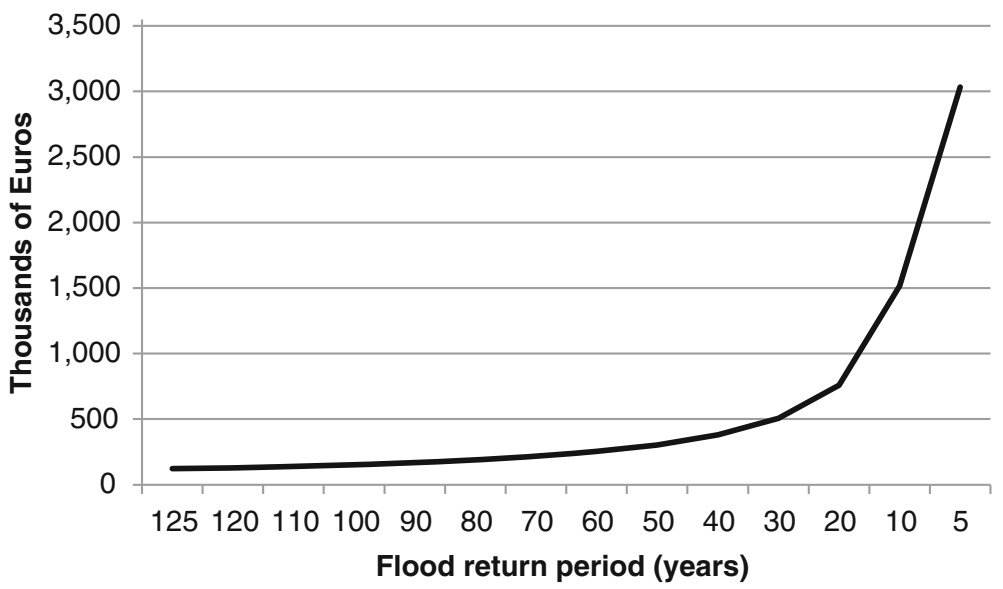

Fig. 4 Willingness to accept compensation for the discomfort, fear and stress experienced during controlled flooding at different flood probabilities 
thousand Euros, while for a further increase to once every 10 years, the required compensation is five times higher (1.5 million Euros). In the case of inundation depth, respondents demanded on average 1,179 Euros compensation for every centimetre increase. For every extra week they would have to be evacuated they demanded 27,646 Euros compensation for the discomfort per household per flood event.

No other explanatory variables had a significant effect on choice behaviour. In case flood probability was modelled as a linear effect, two additional variables appeared to have a significant impact: respondents' trust in existing flood disaster plans for the area where they lived influenced choices in that case in a positive way (the more trust respondents had, the higher the likelihood they accepted controlled flooding and the offered financial compensation), while women were in that case significantly less inclined than men to choose for controlled flooding if inundation depth increased (i.e. feared inundation depth more and hence valued controlled flooding less). However, this model resulted in a lower statistical fit than the model presented in Table 4.

\section{Conclusions}

The study presented in this paper focused on public perception and valuation of climate change flood risks, alternative adaptation and mitigation strategies to cope with the expected increase of these risks, and their effect on human well-being in a highly developed flood prone country. The immaterial well-being effects of climate change risk mitigation addressed in this study are missing in most economic reviews, which focus primarily on the material implications of climate change adaptation and mitigation like house and property flood damage. The study's main objective was to simulate household choice behavior under varying climate change induced flood risks with the help of choice experiments and assess the external (non-market) costs and benefits of climate change risk mitigation and disaster management options. To our knowledge this is one of the first studies to capture the economic value related to these immaterial well-being effects with the help of choice experiments.

Economic welfare measures were estimated related to society's WTP to reduce climate change induced flood risks through private insurance, and WTAC for an increase of these risks through controlled flooding under varying future risk exposure levels. Material damage was covered in the insurance policy experiment, whereas the experiment examining WTAC for controlled flooding tried to capture the economic value of immaterial flood damage, such as feelings of discomfort, fear, stress and social disruption. The latter were related to inundation depth and evacuation period as separate attributes in the choice experiment. Demand for life insurance related to the presented flood risks was not significant, but demand for an evacuation was. Evacuation period was only taken into consideration as a factor of discomfort in the case of controlled flooding, and played no significant role in demand for flood insurance.

The WTP and WTAC results are not comparable for a number of obvious reasons. The WTAC results refer to immaterial welfare losses such as the expected stress and discomfort associated with controlled flooding, while the WTP results also cover the risk of material damage and possible loss of life. Furthermore, the study areas and the baseline risk levels in these areas are different. This too undermines a straightforward comparison of absolute welfare changes.

The results of this study imply a more prominent role of the social damage costs in costbenefit analysis of climate change and flood mitigation policies. The findings show that WTP 
and WTAC are substantial, with WTP for flood insurance depending inter alia on where people live (along the coast or the river), their risk perception, and income level. WTAC for controlled flooding depends exponentially on flood probabilities. Hence, people are willing to pay a positive amount of money for flood risk insurance such as home contents and building insurance, and willing to accept compensation for immaterial damage due to the increased risk of controlled flooding. A remarkable finding is the similarity of the size of public WTP to insure houses against flood risks compared to what people actually paid to insure their houses against damages from other insurable risks, suggesting that our results are reliable.

The observed spatial differences in WTP for flood risk insurance across different risk zones are expected to be relevant for effective marketing of private insurance. However, the question remains whether WTP is large enough for a new insurance market to be viable, especially given the high flood probabilities used in this study. Combined with the skewed distribution of the welfare losses and disruption costs upstream in case of controlled flooding and the corresponding economic benefits downstream, this poses a number of interesting challenges to policy and decision-makers alike to manage the spatial equity issues concerned across the public and private parties involved.

Open Access This article is distributed under the terms of the Creative Commons Attribution License which permits any use, distribution, and reproduction in any medium, provided the original author(s) and the source are credited.

Annex: Representation of the climate change scenarios and associated flood risks in the flood insurance choice experiment

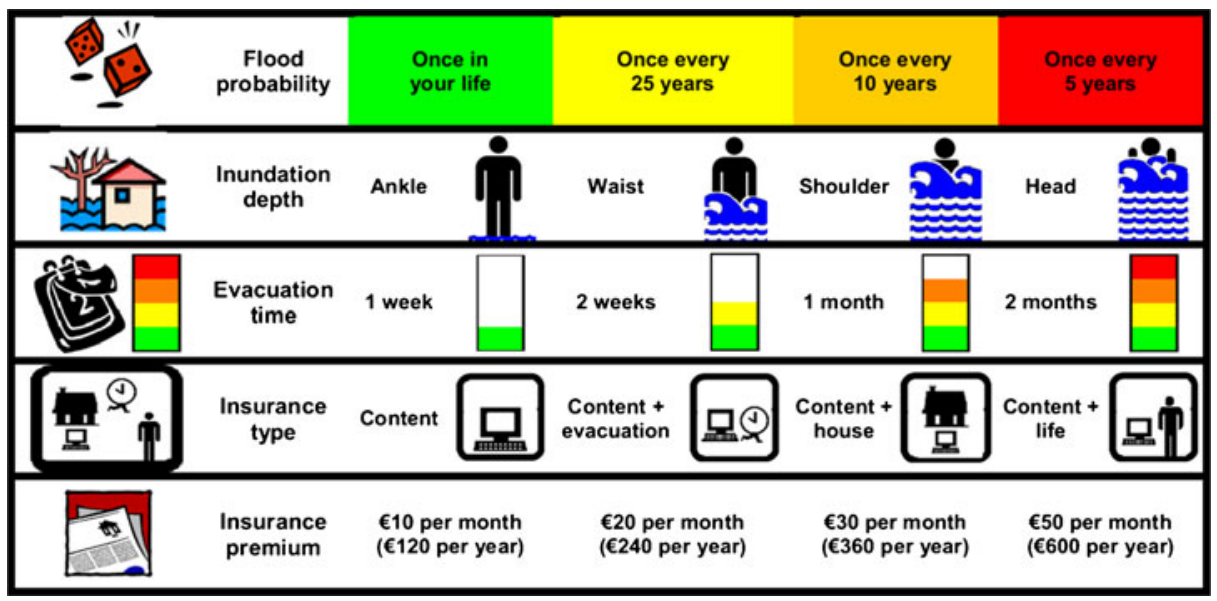

\section{References}

Aerts CJH, Botzen WJ (2011) Climate change impacts on pricing long-term insurance: a comprehensive study for the Netherlands. Glob Environ Chang. doi:10.1016/j.gloenvcha.2011.04.005

Akter S, Brouwer R, Choudhury S, Aziz S (2009) Is there a commercially viable market for crop insurance in rural Bangladesh? Mitig Adapt Strateg Glob Chang 14(3):215-229 
Akter S, Brouwer R, van Beukering P, Silver E, French L, Choudhury S, Aziz S (2011) Exploring the feasibility of private micro flood-insurance provision in Bangladesh. Disasters 35(2):287-307

Arrow K, Solow R, Portney PR, Leamer EE, Radner R, Schuman H (1993) Report of the NOAA Panel on Contingent Valuation. Fed Regist 58(10):4601-4614

Bateman IJ, Carson RT, Day B, Hanemann M, Hanley N, Hett T, Jones-Lee M, Loomes G, Mourato S, Ozdemiroglu E, Pearce DW, Sugden R, Swanson J (2002) Economic valuation with stated preference techniques: a manual. Edward Elgar, Cheltenham

Bateman IJ, Brouwer R, Hanley N, Georgiou S, Machado M, Mourato S, Saunders C (2005) A 'natural experiment' approach to contingent valuation of private and public UV health risk reduction strategies in low and high risk countries. Environ Resour Econ 31:47-72

Beattie J, Covey J, Dolan P, Hopkins L, Jones-Lee M, Loomes G, Pidgeon N, Robinson A, Spencer A (1998) On the contingent valuation of safety and the safety of contingent valuation: part 1 - Caveat investigator. J Risk Uncertain 17:5-25

Beckers J, De Bruin K (2011) Analysis of water safety casualties 21st century. Deltares report, Delft, the Netherlands (in Dutch)

Birol E, Koundouri P (eds) (2008) Choice experiments informing environmental policy, a European perspective. Edward Elgar, Cheltenham

Botzen WJW, van den Bergh JCJM (2008) Insurance against climate change and flooding in the Netherlands: present, future and comparison with other countries. Risk Anal 28(2):413-426

Botzen WJW, van den Bergh JCJM (2009) Managing natural disaster risk in a changing climate. Environ Hazards 8:209-225

Botzen WJW, van den Bergh JCJM (2012) Monetary valuation of insurance against flood risk under climate change. Int Econ Rev 53(3):1005-1025

Brouwer R, Akter S (2010) Informing micro insurance contract design to mitigate climate change catastrophe risks using choice experiments. Environ Hazards 9:74-88

Brouwer R, Kind J (2005) The costs and benefits of flood control policy in the Netherlands. In: Brouwer R, Pearce DW (eds) Cost-benefit analysis and water resources management. Edward Elgar, Cheltenham, pp 93-123

Brouwer R, Schaafsma M (2012) The economics of flood disaster management in the Netherlands. In: Guha Sapir P, Santos I, Borde A (eds) Natural disasters: do they cost the earth? Oxford University Press

Brouwer R, van Ek R (2004) Integrated ecological, economic and social impact assessment of alternative flood protection measures in the Netherlands. Ecol Econ 50(1-2):1-21

Brouwer R, Akter S, Brander L, Haque E (2009) Economic valuation of flood risk exposure and flood risk reduction in a severely flood prone Developing Country. Environ Dev Econ 14(3):397-417

Browne MJ, Hoyt RE (2000) The demand for flood insurance: empirical evidence. J Risk Uncertain 20 (3):291-306

Carson RT, Louviere J (2011) Environmental and resource economics

Dekker T, Brouwer R, Hofkes M, Moeltner K (2011) The effect of risk context on the statistical value of life, a Bayesian meta-model. Environ Resour Econ 49(4):597-624

Dutch Insurance Industry (2011) Dutch insurance industry in figures. The Hague, the Netherlands (in Dutch)

Ferrini S, Scarpa R (2007) Designs with a priori information for nonmarket valuation with choice experiments: a Monte Carlo study. J Environ Econ Manag 53(3):342-363

Ganderton PT, Brookshire DS, McKee M, Stewart S, Thurston H (2000) Buying insurance for disaster-type risks: experimental evidence. J Risk Uncertain 10:271-289

Hanley N, Wright RE, Adamowicz V (1998) Using choice experiments to value the environment. Environ Resour Econ 11(3-4):413-428

Hensher DA, Rose JM, Greene WH (2005) Applied choice analysis, a primer. Cambridge University Press, Cambridge

Hynes S, Hanley N, Scarpa R (2008) Effects on welfare measures of alternative means of accounting for preference heterogeneity in recreational demand models. Am J Agric Econ 90(4):1011-1027

Jonkman SN (2007) Loss of life estimation in flood risk assessment, theory and applications. PhD thesis, Technical University Delft

Kind J (2011) Social cost benefit analysis water safety 21st century. Deltares report, Utrecht, the Netherlands (in Dutch)

Kok M, Huizinga H, Vrouwenvelder A, van den Braak W (2005) Standard method 2005, Damage and casualties as a result of flooding. HKV Lijn in Water and TNO Bouw report, Lelystad, the Netherlands (in Dutch)

Krinsky I, Robb AL (1986) On approximating the statistical properties of elasticities. Rev Econ Stat 68:715719 
Kunreuther HC, Michel-Kerjan EO, Doherty NA, Grace MF, Klein RW, Pauly MV (2009) At war with the weather: Managing large-scale risks in a new era of catastrophes. MIT Press

Loomis JB, duVair P (1993) Evaluating the effect of alternative risk communication devices on willingness to pay: results from a dichotomouc choice contingent valuation experiment. Land Econ 69:287-298

Louviere JJ, Hensher DA, Swait JD (2000) Stated choice methods: analysis and application. Cambridge University Press

Maaskant B, Jonkman SN, Bouwer LM (2009) Future risk of flooding: an analysis of changes in potential loss of life in South Holland (the Netherlands). Environ Sci Policy 12:157-169

McFadden D, Train K (2000) Mixed MNL models for discrete response. J Appl Econ 15:447-470

Michel-Kerjan E, Kousky C (2010) Come rain or shine: evidence on flood insurance purchases in Florida. J Risk Insur 77:369-397

Middelkoop H, Daamen K, Gellens D, Grabs W, Kwadijk JCJ, Lang H, Parmet BWA, Schädler B, Schulla J, Wilke K (2001) Impact of climate change on hydrological regimes and water resources management in the Rhine basin. Clim Chang 49(2-3):105-128

Ministry of Infrastructure and Environment (2011) Water in Beeld, Voortgangsrapportage Nationaal Water Plan over het jaar 2010. The Hague, the Netherlands

Ministerie Verkeer en Waterstaat (2003) Procesplan zwakke schakels in de Nederlandse kust. Bestuurlijk Overleg Kust, 31 January 2003. Ministry of Transport, Public Works and Water Management, The Hague, the Netherlands

Pearce DW, Smale R (2005) Appraising flood control investments in the UK. In: Brouwer R, Pearce DW (eds) Cost-benefit analysis and water resources management. Edward Elgar, Cheltenham

Provencher B, Bishop RC (2004) Does accounting for preference heterogeneity improve the forecasting of a random utility model? J Environ Econ Manag 48(1):793-810

Shogren J, Crocker T (1991) Risk, self-protection, and ex ante valuation. J Environ Econ Manag 20:1-15

Sjöberg L (2002) Policy implications of risk perception research: a case of the emperor's new clothes? Risk Manag 4:11-20

Slovic P (1987) Perception of risk. Science 236(4799):280-285

Statistics Netherlands (2007) Statline. www.cbs.nl

Stern N (2006) The economics of climate change: the Stern review. Cambridge University Press

Train K (2003) Discrete choice methods with simulation. Cambridge University Press

Tversky A, Kahneman D (1979) Prospect theory: an analysis of decision under risk. Econometrica 47:263291

van den Hurk BJJM, Klein Tank AMG, Lenderink G, van Ulden A, van Oldenborgh GJ, Katsman C, van den Brink H, Keller F, Bessembinder J, Burgers G, Komen G, Hazeleger W, Drijfhout S (2007) New climate change scenarios for the Netherlands. Water Sci Technol 56(4):27-33

Wilson AR (1991) Environmental risk: identification and management. Lewis, Chelsea 